\title{
A computer-based quantitative systems pharmacology model of negative symptoms in schizophrenia: exploring glycine modulation of excitation-inhibition balance
}

\author{
Athan Spiros ${ }^{1}$, Patrick Roberts ${ }^{1,2}$ and Hugo Geerts ${ }^{1,3}$ * \\ ${ }^{1}$ Computational Neuropharmacology, In Silico Biosciences, Inc., Berwyn, PA, USA \\ ${ }^{2}$ Department of Biomedical Engineering, Oregon Health and Science University, Portland, OR, USA \\ ${ }^{3}$ Department of Laboratory Pathology, Perelman School of Medicine, University of Pennsylvania, Philadelphia, PA, USA
}

\section{Edited by:}

Tarek A. Leil, Bristol-Myers Squibb, USA

\section{Reviewed by:}

Ronald P. Hammer, University of

Arizona College of Medicine,

Phoenix, USA

Barry Horwitz, National Institutes of Health, USA

\section{*Correspondence:}

Hugo Geerts, Computational

Neuropharmacology, In Silico

Biosciences, Inc., 686 Westwind

Dr., Berwyn, PA 19312, USA

e-mail: hugo-geerts@

in-silico-biosciences.com
Although many antipsychotics can reasonably control positive symptoms in schizophrenia, patients' return to society is often hindered by negative symptoms and cognitive deficits. As an alternative to animal rodent models that are often not very predictive for the clinical situation, we developed a new computer-based mechanistic modeling approach. This Quantitative Systems Pharmacology approach combines preclinical basic neurophysiology of a biophysically realistic neuronal ventromedial cortical-ventral striatal network identified from human imaging studies that are associated with negative symptoms. Calibration of a few biological coupling parameters using a retrospective clinical database of 34 drug-dose combinations resulted in correlation coefficients greater than 0.60 , while a robust quantitative prediction of a number of independent trials was observed. We then simulated the effect of glycine modulation on the anticipated clinical outcomes. The quantitative biochemistry of glycine interaction with the different NMDA-NR 2 subunits, neurodevelopmental trajectory of the NMDA-NR $2 B$ in the human schizophrenia pathology, their specific localization on excitatory vs. inhibitory interneurons and the electrogenic nature of the glycine transporter resulted in an inverse U-shape dose-response with an optimum in the low micromolar glycine concentration. Quantitative systems pharmacology based computer modeling of complex humanized brain circuits is a powerful alternative approach to explain the non-monotonic dose-response observed in past clinical trial outcomes with sarcosine, D-cycloserine, glycine, or D-serine or with glycine transporter inhibitors. In general it can be helpful to better understand the human neurophysiology of negative symptoms, especially with targets that show non-monotonic dose-responses.

Keywords: schizophrenia, negative symptoms, glycine, computer model, dose-response relationship, drug

\section{INTRODUCTION}

Negative symptoms in schizophrenia are a major cause of functional deficit for patients wanting to return to professional life. While many of the approved antipsychotics can control the positive symptoms, negative symptom dysfunction is often not addressed properly by drug therapy alone (Rosenbaum et al., 2012). In addition, there are species differences for animal models that have large ramifications for drug development in

\footnotetext{
Abbreviations: ASL-fMRI, Arterial Spin Labeling functional Magnetic Resonance Imaging; BOLD-fMRI, Blood Oxygen Level Dependent functional Magnetic Resonance Imaging; CBF, Cerebral Blood flow; DA, Dopamine; dlPFC, dorsolateral Prefrontal Cortex; $\mathrm{EC}_{50}$, concentration at which $50 \%$ of maximal effect is reached; Enk, encephalin; ER, endoplasmic reticulum; GlyT1, Glycine Transporter subtype $1 ; \mathrm{mAChR}$, muscarinic acetylcholine receptor; $\mathrm{mGluR}$, metabotropic glutamate receptor; MSN, Medium Spiny Neuron (major cell type in striatum); NMDA, N-methyl-D-aspartate (glutamate receptor subtype); PANSS, Positive and Negative Symptoms Scale in schizophrenia; PDSP, Psycho-active Drug Screening Program; PET, Positron Emission Tomography; PFC, Prefrontal Cortex; PSD95, postsynaptic density complex; QSP, Quantitative Systems Pharmacology; SP, Substance P; vmPFC, ventro-medial Prefrontal Cortex.
}

schizophrenia (Peleg-Raibstein et al., 2012) and consequently psychiatric disorders have one of the lowest probabilities of clinical success, close to 7\% (Hay et al., 2014). Because of these limitations, companies are de-emphasizing psychiatric diseases (Hyman, 2014), suggesting a need for completely novel technologies.

Negative symptoms can be divided in two moderately correlated factors (Horan et al., 2011): experiential impairments (diminished motivation and enjoyment of social, vocational, and recreational activities) and expressive impairments (diminished non-verbal and verbal communication). Experiential impairments are best represented by avolition and anhedonia, while expressive impairments are related to flat affect. Both these dimensions play an important role in the clinical phenotype.

Glutamate modulation through increased glycine mediated stimulation of the NMDA-R has been proposed as a strategy for addressing negative symptoms in schizophrenia. Consequently, a number of glycine modulators have been studied in clinical trials. In humans, the GlyT1 inhibitor ORG25935 reduced 
the ketamine-induced increases in measures of psychosis and perceptual alterations with an effect size of 0.71 and 0.98 , respectively, but worsened some aspects of learning and delayed recall (D'Souza et al., 2012). Studies with the GlyT1 inhibitor GSK1018921 suggested that target engagements up to $80 \%$ were well tolerated (Ouellet et al., 2011). The Janssen GlyT1 inhibitor R213129 enhanced scopolamine-induced finger tapping impairment in healthy volunteers, while electroencephalography alpha power was increased and scopolamine-induced impairment of the Stroop test was partly reversed (Liem-Moolenaar et al., 2010). The Pfizer GlyT1 inhibitor PF03463275 was ineffective at the highest dose (NIH NCATS website http://www.ncats.nih. gov/research/reengineering/rescue-repurpose/therapeuticuses/ directory.html).

In a meta-analysis with 800 subjects from 26 studies, glycine, D-serine, and sarcosine had effect sizes ranging from 0.40 in negative symptoms to 0.28 for cognitive and 0.26 for positive symptoms, whereas D-cycloserine did not improve any symptom domain. Interestingly, patients on risperidone or olanzapine, but not clozapine, improved (Tsai et al., 2004).

Glycine directly activates the glycineB site on the NMDA-R, but needs to be given in large quantities; D-serine is another endogenous activator of the NMDA-R on a different binding site and sarcosine was found to be a GlyT1 inhibitor (Wolkenberg and Sur, 2010). The absence of target engagement data in these clinical trials makes it difficult to interpret the clinical outcome.

Preclinical data on cognitive effects together with target engagement studies in non-human primates for two GlyT1 inhibitors strongly suggest an inverse U-shape dose-response (Eddins et al., 2014); in this study the highest doses consistently failed to improve cognition and bitopertin was found to be effective only at the lowest and medium doses, but not at the highest dose. An inverse U-shape dose-response is a difficult property for any clinical trial development; although such a dose-response is often observed in preclinical animal models, it is often difficult to relate this to actual human target engagement levels. Therefore, exploring the neurophysiology of such complex dose-responses in a humanized translational model is of crucial importance to drug development. In this report we will use an in silico quantitative systems pharmacology model (Geerts et al., 2013b) that integrates preclinical information with clinical neuropathology, imaging, and clinical data and that has been successful for cognitive enhancements in schizophrenia (Geerts et al., 2013a) and Alzheimer's disease (Roberts et al., 2012; Nicholas et al., 2013) and for motor side-effects of new antipsychotics (Geerts et al., 2012).

The remainder of the introduction will be devoted to the biological rationale for identifying the brain regions and neurophysiological processes that play a role in the clinical phenotype of negative symptoms. Unlike preclinical animal models, we will use predominantly imaging studies from patients and their relationship to clinical scales.

\section{BIOLOGICAL RATIONALE FOR COMPUTER MODEL OF NEGATIVE SYMPTOMS \\ Brain regions/neurophysiology involved in negative symptoms}

The prefrontal cortex and ventral striatum are key brain regions involved in the processing of negative symptoms. From ASL-fMRI imaging studies to measure cerebral blood flow (CBF) in schizophrenic patients on antipsychotics medications (Pinkham et al., 2011), hypofrontality was most prominent in individuals with more severe negative symptoms. A large meta-analysis of 25 imaging studies (Goghari et al., 2010) suggests an inverse correlation between BOLD-fMRI activity of the ventromedial cortex and the degree of negative symptoms. Metabolic activity, measured by PET imaging, is reduced as negative symptoms increase in patients without antipsychotics (Wolkin et al., 1992) and physical anhedonia scale scores were negatively correlated with the hypoactive dorsomedial PFC metabolism (Park et al., 2009).

Another study suggests that activity of R. orbitofrontal cortex, but not anterior cingulate correlates with the self-reported Chapman Physical Anhedonia Scale (Harvey et al., 2010). As anhedonia together with avolition and apathy form the more "experiental" factor in negative symptoms, as opposed to flat affect that is more "expressive" (Horan et al., 2011); this suggests that lower activity of the R. orbitofrontal dysfunction might play a role in negative symptoms. Moreover, an inverse correlation of negative symptoms with R. anterior prefrontal cortex activity at rest (Mingoia et al., 2012) suggests that basal cortical activity is proportionally lower in patients with predominantly negative symptoms but the identity of the cortical region depends upon the task involved or the measurement condition.

This overview suggests that the cortical activity especially of the vmPFC and the right orbitofrontal cortex is lower in schizophrenia patients, and that increased activation might correspond to improved symptoms.

Imaging studies of ventral striatum pathology in schizophrenia (Menon et al., 2001; Harvey et al., 2010) suggest a profound and proportional dysfunction, with more negative symptoms associated with decreased activation level. In patients, lower ventral striatum activation in patients is proportional to the severity of negative symptoms, an effect that is independent of medication (whether medication-free, on typical or atypical antipsychotics) (Juckel et al., 2006a,b). In schizophrenia patients in psychotic remission (Sorg et al., 2013) basal activity of the ventral striatum is increased and this increase is correlated with improvements of negative symptoms such as emotional withdrawal and blunted affect.

\section{Cellular localization of NMDA-NR2 subunits}

The activity of the cortical region is driven by pyramidal cell firing in general and by glutamatergic action in particular. Therefore, NMDA-R is an interesting target for negative symptoms. However, because the cortical activity is defined by the balance of excitation over inhibition, it is of interest to take into account the differential localization of NMDA-R on pyramidal cells and interneurons in cortical circuits. mRNA localization studies of different NMDA-NR2 subunits in the rat and mice hippocampus, suggest that $\mathrm{NR}_{2} \mathrm{C} / 2 \mathrm{D}$ are localized on inhibitory interneurons while $\mathrm{NR}_{2 \mathrm{~A}} / \mathrm{NR}_{2 \mathrm{~B}}$ seem to be more concentrated on pyramidal cells (Monyer et al., 1994). Functional evidence was provided by elimination of $\mathrm{NR}_{2} \mathrm{C}$ subunit having no effect on the strongly rectifying NMDA current in pyramidal cells of the prefrontal cortex (Zhang et al., 2012). 
Reelin deficient heterozygous mice showed significantly enhanced MK-801-induced locomotor hyperactivity and startle, which was associated with significant up-regulation of $\mathrm{NR}_{1}$ subunits, but down-regulation of $\mathrm{NR}_{2} \mathrm{C}$ subunits in the frontal cortex (van den Buuse et al., 2012), suggesting that loss of activity on inhibitory neurons through reduced NMDA- $\mathrm{NR}_{2 \mathrm{C}}$ synapses leads to a lower GABA tone, a functional disinhibition, and a higher locomotor activity. These and other preclinical data strongly suggests that while $\mathrm{NR}_{2 \mathrm{~A}}$ and $\mathrm{NR}_{2 \mathrm{~B}}$ are expressed on pyramidal excitatory cells, the $\mathrm{NR}_{2 \mathrm{C}}$ subunit is localized on inhibitory neurons.

\section{Change of NMDA subunits with schizophrenia pathology}

The NR2B subunit is upregulated during neurodevelopment of the brain and is likely to play a relatively larger role in schizophrenia, in line with the neurodevelopmental hypothesis of schizophrenia pathology. Indeed in postmortem dorso-lateral prefrontal cortex samples of schizophrenia patients vs. healthy control, increased phosphorylation of $\mathrm{NR}_{2 \mathrm{~B}}$ at $\mathrm{Y} 1336$ is found (Funk et al., 2012), probably leading to a higher functional activity by reducing endocytosis (Jiang et al., 2011; Li et al., 2011). In patients with schizophrenia, a significant effect of GRIN2B (human NMDA receptor $2 \mathrm{~B}$ subunit gene, $\mathrm{NR}_{2 \mathrm{~B}}$ ) genotype on habituation (Hokyo et al., 2010) suggests a bigger role for $\mathrm{NR}_{2 B}$ mediated processes.

Altered expression of mRNA for proteins involved in in microtubule-associated tracking complex of $\mathrm{NR}_{2 \mathrm{~B}}$ such as KIF17, APBA1, CASK, mLin7A, and mLin7C in cortical layers III and IV of schizophrenia patients, which overlapped with $\mathrm{NR}_{2 \mathrm{~B}}$ but not $\mathrm{NR}_{2 \mathrm{~A}}$ transcripts suggests that $\mathrm{NR}_{2 \mathrm{~B}}$ containing NMDA receptor transport could be selectively compromised in schizophrenia (Kristiansen et al., 2010a,b). In a subcellular endoplasmic reticulum (ER)-enriched fraction from postmortem brain, ER expression of $\mathrm{NR}_{2 \mathrm{~B}}$ and PSD-95 was decreased in dorsolateral prefrontal cortex in schizophrenia. The data suggest that changes in $\mathrm{NR}_{2 \mathrm{~B}}$ processing in schizophrenia involve increased ER exit of $\mathrm{NR}_{2 \mathrm{~B}}$ containing NMDA receptors suggesting a higher membrane expression level (Kristiansen et al., 2010b).

Furthermore, a cross-sectional study of over 900 human brains from the publicly available BrainCloud website (http:// braincloud.jhmi.edu/) suggests an increase in cortical mRNA for the $\mathrm{NR}_{2 \mathrm{~B}}$ subunit during the adolescent period (10-20 years) that reverts for older brains. This suggests that during neurodevelopment the $\mathrm{NR}_{2 \mathrm{~B}}$ subunit is upregulated in the human brain but its expression tends to decrease with age.

In summary these data suggest that the NMDA- $\mathrm{NR}_{2 B}$ subunit is upregulated in schizophrenia patients.

\section{GLYCINE TRANSPORTER PHYSIOLOGY}

In order to estimate the range of free glycine level that can be readily achieved in the living human brain, we need to consider the neurophysiology of the glycine transporter T1, found mostly on astrocytes but also on neuronal cells and is a co-transporter system driven by the electrogenic movement of $2 \mathrm{Na}^{+}$and $1 \mathrm{Cl}^{-}$ over the cell membrane at a slow turnover rate of 10/s (Cherubino et al., 2010). Kinetics follow Michaelis-Menten dynamics with $K_{m}$ in the range of 10-20 uM (Okamoto et al., 2009; Cherubino et al., 2010).

The astrocyte membrane potential is in the range of $-75 \mathrm{mV}$ (Ma et al., 2014) and does not share the same temporal dynamics as neuronal cells. The membrane can depolarize substantially in the case of ischemic and traumatic brain injury (Strong and Dardis, 2005), but we assume that the astrocyte membrane potential is close to the equilibirum value in schizophrenia.

\section{METHODS \\ RECEPTOR COMPETITION MODEL}

Many antipsychotic drugs on the market have different affinities for multiple receptors, therefore calculating the receptor change for a given exposure level of the drug at each of these receptors is important, because they will affect the membrane potential of key neuronal circuits and their emergent properties.

The receptor model simulates the competition between endogenous neurotransmitter and up to four agents, (for instance two drugs with their metabolites or a drug and radioactive tracer) at postsynaptic receptors with full presynaptic autoreceptor coupling to neurotransmitter release based on the affinities of the drug for all receptors in the synaptic cleft (Spiros et al., 2010). This is performed using a set of ordinary differential equations that takes into account different neurotransmitter release patterns and modulated by presynaptic autoreceptors, including presynaptic facilitation and depression processes. The dopaminergic synapse is further calibrated (Spiros et al., 2010) using data on dopamine dynamics measured with fast cyclic-voltammetry in monkey slices (Cragg et al., 2000) and human cortical imaging data (Slifstein et al., 2008), while the serotonin synapse with $5-\mathrm{HT}_{1 \mathrm{~B}}$ as a presynaptic autoreceptor is calibrated using a combination of preclinical fast cyclic voltammetry constrained by human imaging data (Roberts et al., 2012).

The affinity parameters for each antipsychotic and neurotransmitter for human receptors were derived from the in vitro experiments performed at the Psychoactive Drug Screening Program (PDSP) and reported in the PDSP database (http://pdsp.med. unc.edu/indexR.html) with the advantage that the affinity values are derived under the same standardized assay conditions. For different values of target engagement (e.g., $\mathrm{D}_{2} \mathrm{R}$ occupancy), we then calculated the change of postsynaptic receptor activation for all the receptors involved in the computer model based on the affinities of the drug for different receptors.

\section{CORTICAL-STRIATAL MODEL FOR NEGATIVE SYMPTOMS}

Based on the human imaging studies, we developed a dual cortical-striatal model for the neurobiology of negative symptoms (Figure 1). The cortical neuronal network consists of 20 excitatory neurons and 10 inhibitory interneurons and has been described before (Geerts et al., 2013a). This model has been calibrated from in vivo single-unit recordings in primates during a working memory task and reduces some of the problems associated with species difference in inhibitory tone. Synchronous firing of the target pyramidal cells is initiated by injecting a transient current at $t=2000 \mathrm{~ms}$. The network then fires in a synchronized pattern before it gets degraded by the background noise and the interference of the distractor neurons. The simulated 


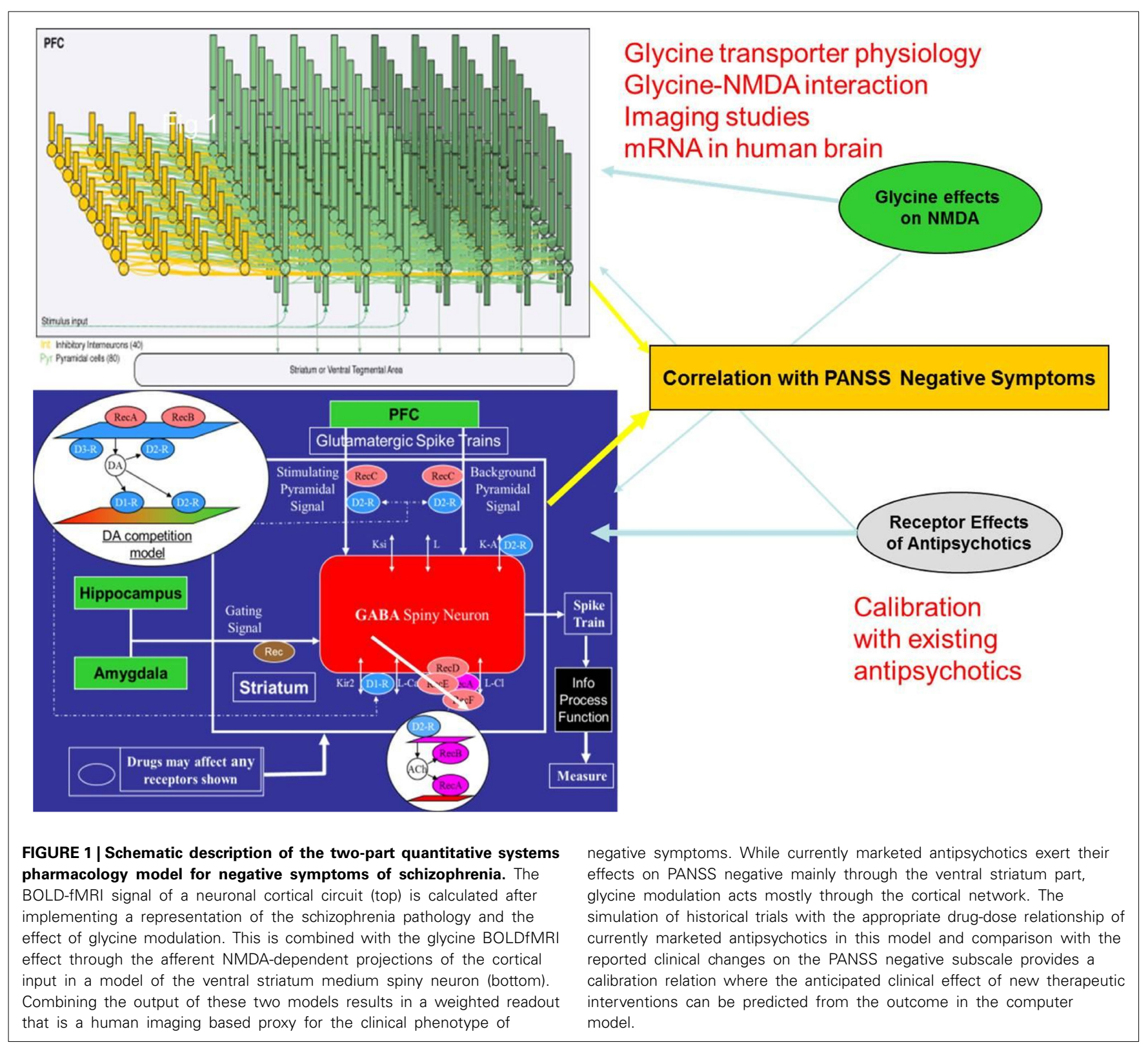

neural activity represents the right orbitofrontal cortex or the vmPFC.

Functional representations, driven by preclinical experiments on the coupling between receptor activation and changes in voltage-gated ion channel conductance, of the dopamine $\left(D_{1}\right.$, $\left.\mathrm{D}_{2}, \mathrm{D}_{3}, \mathrm{D}_{4}, \mathrm{DAT}, \mathrm{COMT}\right)$, serotonin $\left(5 \mathrm{HT}_{1} \mathrm{~A}, 5 \mathrm{HT}_{1} \mathrm{~B}, 5 \mathrm{HT}_{2} \mathrm{~A}\right.$, $\left.5 \mathrm{HT}_{2} \mathrm{C}, 5 \mathrm{HT}_{3}, 5 \mathrm{HT}_{4}, 5 \mathrm{HT}_{6}, \mathrm{SERT}\right)$, norepinephrine (alpha 1 A, alpha $\left._{2} \mathrm{~A}, \mathrm{NET}\right)$, cholinergic $\left(\mathrm{M}_{1} \mathrm{mAChR}, \mathrm{M}_{2} \mathrm{mAChR}, \alpha_{7}\right.$ nAChR, $\alpha_{4} \beta_{2}$ nAChR, and AChE), glutamate NMDA (different subunits NR2A-NR2B-NR2C), AMPA, mGluR2, mGluR5, GlyT1, GABA-A $\alpha_{1}$ and GABA-A $\alpha_{2}$, histamine $\mathrm{H}_{3}$ and PDE-10 targets are currently implemented in the model.

Although the intracellular pathways activated by receptor modulation are not modeled in full detail, we implement the effects as a transfer function on ion channel permeability or

transporter functionality. For instance a change in dopamine $\mathrm{D}_{1} \mathrm{R}$ activation on cortical neurons is implemented by changing the slow $\mathrm{K}^{+}$channel $I_{k s}$ conductance (Yang and Seamans, 1996) and the High-voltage activated (Hva) $\mathrm{Ca}^{++}$-channel, based on preclinical electrophysiological measurements (Law-Tho et al., 1994).

Schizophrenia pathology in the cortical network is introduced as a reduction in glutamate tone (Coyle, 2006), decreased dopamine tone (Meyer-Lindenberg et al., 2002; Weinberger, 2007) in the cortex, impaired GABA physiology through a decrease in GAD67 activity resulting in lower GABA release (Gonzalez-Burgos et al., 2010) and increased background noise level (Winterer et al., 2000). Such a pathology when implemented in the computer model leads to a deterioration of a marker for cognitive outcome of about 1.5 standard deviations (Geerts et al., 
2013a). In this case, rather than the length of time a certain firing pattern can be independently held, the cortical readouts of the model for negative symptoms of schizophrenia is the average firing rate and BOLD-fMRI.

The ventral striatum model has been described in detail as part of the quantitative systems pharmacology platform for schizophrenia (Geerts et al., 2012; Spiros et al., 2012). Briefly, the model calculates the excitability of the medium spiny neuron (MSN), the major GABA-ergic cell type in the nucleus accumbens, when driven by afferent cortical projections and gated by both hippocampal and amygdala projections. Changes in membrane potential are calculated using partial differential equations that are solved in NEURON (Hines and Carnevale, 1997). If $\mathrm{C}$ is the membrane capacitance, then the time course of the membrane potential $\mathrm{V}$ can be determined from the following equation:

$$
C \frac{\partial V}{\partial t}=I_{K s i}+I_{K A}+. I_{C l}+I_{C a}+\ldots
$$

where $I_{X}$ is the current associated with channel X.

We simulate three types of neuronal MSN cells: $\mathrm{SP}^{+}=\mathrm{D}_{1} \mathrm{R}^{+}$ cells that project to the direct pathway; $\mathrm{Enk}^{+}=\mathrm{D}_{2} \mathrm{R}^{+}$cells that project to the indirect pathway; and a small number of $\mathrm{D}_{1}^{+} \mathrm{D}_{2}^{+}$ cells that project to both pathways. In the $\mathrm{SP}^{+}$cells the $\mathrm{D}_{1} \mathrm{R}$ mostly affects the $K_{i r 2}$ channel and increases the L-type $\mathrm{Ca}^{++}$ current (Hernandez-Lopez et al., 2000), while in Enk ${ }^{+}$cells, $\mathrm{D}_{2} \mathrm{R}$ activation affects the A-type $\mathrm{K}^{+}$current (Falk et al., 2006). In addition, $\mathrm{D}_{2} \mathrm{R}$ activity modulates the presynaptic Glu release on the afferent cortical fibers (O'Donnell and Grace, 1994; Bamford et al., 2004).

For instance, the inward rectifying potassium current, Kir2, is modified by the dopamine $\mathrm{D}_{1} \mathrm{R}$ activation $\mathrm{u}$ (Kuzhikandathil and Oxford, 2002; Falk et al., 2008) so that the total current, $I=u \cdot I_{K i r 2}$. With a conductance, $g_{K}$, and a reversal potential, $E_{K}=-90 \mathrm{mV}$, the current is given by $I_{K i r 2}=g_{K}\left(V-E_{K}\right)$ with a voltage dependent form

$$
g_{K}=\bar{g}_{K} \frac{1}{1+\exp \left(-\frac{V-V_{h}^{K}}{V_{c}^{K}}\right)}
$$

where $\bar{g}_{K}=1.2 \mathrm{mS} / \mathrm{cm}^{2}$ is the maximum conductance, $V_{h}=-111 \mathrm{mV}$ is the value of the membrane potential that causes half activation and $V_{c}=-11 \mathrm{mV}$ describes the sensitivity of the change (Mermelstein et al., 1998; Gruber et al., 2003).

The amount of DA released in the striatal dopaminergic synapse is increased by $5-\mathrm{HT}_{2} \mathrm{C}$ receptor inhibition (Abdallah et al., 2009), while 5- $\mathrm{HT}_{3} \mathrm{R}$ antagonism decreases striatal DA (De Deurwaerdere et al., 1998; Porras et al., 2003). Cholinergic modulation affects the excitability of MSN through an effect on Cl- channel (Shen et al., 2005, 2007) through postsynaptic $\mathrm{M}_{1} \mathrm{R}$ mAChR. In addition, $\mathrm{M}_{2} \mathrm{mAChR}$ located on corticostriatal terminals (Hersch et al., 1994) inhibit the glutamatergic input to MSNs (Malenka and Kocsis, 1988; Sugita et al., 1991; Calabresi et al., 1998; Hernandez-Echeagaray et al., 1998). Adrenergic alpha $_{1 \mathrm{~A}}-\mathrm{R}$ block decreases gating signal stimulation of the GABA spiny neuron (Braga et al., 2004; Aroniadou-Anderjaska et al., 2007). All these processes are implemented using the appropriate differential equations with a linear relationship between the increase of DA and normalized activation level.

\section{IMPLEMENTATION OF THE BOLD-fMRI READOUT}

In order to calculate a measure of the BOLD-fMRI outcome from the computer model, we implemented a series of biophysical relations between excitatory and inhibitory neuronal activity as determined by experimental studies (Sotero and Trujillo-Barreto, 2007, 2008). The relevant equations are implemented describing the relationships between excitatory and inhibitory neuronal activity, glucose consumed, oxygen consumed, and CBF changes to obtain a measure of the BOLD signal with the Balloon model (Buxton et al., 2004; Buxton, 2012) with the parameters provided from a review study (Sotero and Trujillo-Barreto, 2008).

With $v(t)$ the normalized cerebral blood volume, $f(t)$ the normalized CBF and $q(t)$ the doxyhemoglobin content, the BOLDfMRI signal $y(t)$ is described by

$$
\begin{aligned}
y(t) & =V 0\left(a_{1}(1-q)-a_{2}(1-v)\right. \\
\text { With } \frac{d v(t)}{d t} & =\frac{1}{t_{0}}\left(f(t)-f_{\text {out }}(v, t)\right) \\
\frac{d q(t)}{d t} & =\frac{1}{t_{0}}\left(m(t)-f_{\text {out }}(v, t) \frac{q(t)}{v(t)}\right) \\
\text { fout }(v, t) & =v \exp \left(\frac{1}{a}\right)+\tau d v(t) / d t
\end{aligned}
$$

Furthermore, with $m_{e}(t)$ and $m_{i}(t)$ the metabolic rate of oxygen consumption from excitatory and inhibitory cells, respectively

$$
\begin{aligned}
m(t) & =\left(\gamma m_{e}(t)+m_{i}(t)\right) /(\gamma+1) \\
m_{i}(t) & =g_{i}(t) \text { and } m_{e}(t)=g_{e}(t)(2-x(t)) /(2-x o) \\
\text { And } g(t) & =\left(2 \gamma g_{e}(t)+(2-x o) g_{i}(t)\right) /(2 \gamma+2-x o)
\end{aligned}
$$

With $u_{e}(t)$ and $u_{i}(t)$ the excitatory and inhibitory neuronal activity, both $g_{e}(t)$ and $g_{i}(t)$, the glucose level normalized to baseline consumption, are further defined by

$$
\begin{gathered}
\frac{d g_{e}(t)}{d t}=s_{e}(t) \\
\text { and } \frac{d g_{i}(t)}{d t}=s_{i}(t) \text { with } \\
\frac{d s_{e}(t)}{d t}=\frac{a_{e}\left(u_{e}\left(t-\delta_{e}\right)-1\right)}{\tau_{e}}-\frac{2 s_{e}(t)}{\tau_{e}}-\frac{g_{e}(t)-1}{\tau_{e} * \tau_{e}}
\end{gathered}
$$

With an identical equation for $s_{i}(t)$ with all indexes referring to inhibitory interneuron activity $u_{i}(t)$.

The CBF $\mathrm{f}(\mathrm{t})$ is defined by $\frac{d f(t)}{d t}=s(t)$.

Where $\frac{d s(t)}{d t}=\varepsilon\left(e_{e}\left(t-\delta_{f}\right)-1\right)-\frac{s(t)}{\tau_{s}}-\left(f(t)-1 / \tau_{f}\right.$.

Values for the different constants are given in Table 3 of Sotero and Trujillo-Barreto (2008). For instance, $a_{e}$ is the efficacy of glucose consumption response to excitation $(1.2) ; c$ the steepness of 
the sigmoid function (2.5) and $d$ the position of the threshold for the sigmoid function (1.6), $\tau$ the time constant that controls how fast Cerebral Blood volume adjusts to changes in CBF (10 s), $a_{1}$ weight for deoxyhemoglobin change (3.4) and $\mathrm{a}_{2}$ weight for blood volume change (Rosenbaum et al., 2012).

\section{IMPLEMENTATION OF THE GLYCINE NEUROPHYSIOLOGY IN THE MODEL}

The ratio of $\mathrm{NR}_{2 \mathrm{~A}} / \mathrm{NR}_{2 \mathrm{~B}}$ subunit on pyramidal excitatory synapses vs. $\mathrm{NR}_{2} \mathrm{C} / \mathrm{NR}_{2 \mathrm{D}}$ subunit on inhibitory cells is an important driver of glycine modulation. Glycine interacts differently with different NMDA- $\mathrm{NR}_{2}$ subtypes even if the binding site is on the $\mathrm{NR}_{1}$ subunit. The potentiation of NMDA current by glycine has been measured experimentally and can be described by a Hill equation. The NMDA-R conductance $g$ can be described as follows.

$$
g=g_{\max } \frac{[G l y]^{n}}{[G l y]^{n}+\left[E C_{50}\right]^{n}}
$$

With $g_{\max }$ a maximal conductance value, [Gly] the concentration of extracellular glycine and with numerical values for $\mathrm{EC}_{50}$ and Hill slope determined from a number of experimental studies (Kutsuwada et al., 1992; Laurie and Seeburg, 1994; Matsui et al., 1995; Woodward et al., 1995; Chen et al., 2008).

The $\mathrm{EC}_{50}$ (concentration at which effect is $50 \%$ of maximum) and Hill slopes $(n)$ for different experimental conditions are given in Table 1. It will be clear that with different values for the Hill equation and $\mathrm{EC}_{50}$ we get rich dynamics in terms of the ratio of the NMDA currents on pyramidal-pyramidal synapses (mostly $\mathrm{NR}_{2 \mathrm{~A}}-\mathrm{NR}_{2 \mathrm{~B}}$ ) vs. the NMDA currents on pyramidal-inhibitory synapses driven by the $\mathrm{NR}_{2} \mathrm{C}-\mathrm{NR}_{2 \mathrm{D}}$ subunits (see Figure 3 for example).

Table 1 | Experimentally determined values for $\mathrm{EC}_{50}$ and Hill slopes for glycine-glycine site interaction on the NMDA-NR 2 subunit from different experimental conditions.

\begin{tabular}{lccccl}
\hline Parameter & $\mathbf{N R}_{\mathbf{2 A}}$ & $\mathbf{N R}_{\mathbf{2 B}}$ & $\mathbf{N R}_{\mathbf{2 C}}$ & $\mathbf{N R}_{\mathbf{2 D}}$ & References \\
\hline EC $_{50}$ (uM) & 0.97 & 0.84 & 0.75 & 0.56 & Matsui et al., 1995 \\
Hill slope & 1.5 & 2 & 2 & 1 & \\
EC 50 (uM) & 2.1 & 0.3 & 0.2 & & Kutsuwada et al., 1992 \\
Hill slope & 1.5 & 1.5 & 1.5 & & \\
EC $_{50}$ (uM) & 0.84 & 0.19 & 0.15 & 0.096 & Woodward et al., 1995 \\
Hill slope & 1.5 & 2 & 1.5 & 1 & \\
EC & 3.7 & 2.1 & 0.36 & 2.3 & Laurie and Seeburg, 1994 \\
Hill slope & 1. & 1.5 & 1.5 & 1.5 & \\
EC & 1.31 & 0.72 & 0.34 & 0.13 & Chen et al., 2008 \\
Hill slope & 1.66 & 1.84 & 1.81 & 1.32 & \\
\hline Average EC & & & & & \\
Average Hill slope & 1.43 & 1.77 & 1.66 & 1.21 & \\
\hline
\end{tabular}

$E C_{50}$ values are definitely higher and there is a trend for higher Hill slope for excitatory-excitatory $N R_{2 A / B}$ subunits lespecially when considering the $N R_{2 B}$ subunits) over the excitatory-inhibitory $N R_{2 C / D}$ subunits.

\section{CALIBRATION OF THE MODEL WITH CLINICAL DATA ON NEGATIVE SYMPTOMS}

The model is subsequently calibrated using historical clinical trials. Historical clinical data in schizophrenia patients were collected by querying PubMed with the keywords "drug X" and "schizophrenia" and "trial" in the period since 1986. Restricting the data to clinical double-blind placebo-controlled studies on drug monotherapy using stable schizophrenia patients for a short duration (4-12 weeks), resulted in 91 papers and 71 drug-dose combinations. For each drug dose combination, we calculated the change in postsynaptic receptor activation using the receptor competition model using the appropriate affinities of the neurotransmitter, the drug and its metabolite.

We assume a linear normalized relationship between receptor activation and biological effect on physiological responses such as $X_{Y}^{\text {eff }}=\frac{X_{Y}^{A}-X_{Y}^{C}}{X_{Y}^{C}}$; (Equation 13) where $X_{Y}^{A}$ and $X_{Y}^{C}$ are the actual activation levels of receptor $X$ subtype $Y$ (for instance $D_{1}$ ) after treatment (A) and the untreated (placebo) control levels (C).

Such short clinical studies are common in the clinical testing of antipsychotics and motor side effects can arise very early with treatment. For each study, the average outcome of a patient group on the reported clinical trial was entered into a database. In the case of multiply reported results for the same drug-dose, the weighted average outcome based on number of patients was calculated. The list of clinical studies can be requested from the corresponding author.

\section{RESULTS}

\section{CALIBRATION OF THE MODEL FOR NEGATIVE SYMPTOMS OUTCOME}

Extraction of the relevant information from the clinical database results in 34 drug-dose combinations of short-term clinical trials

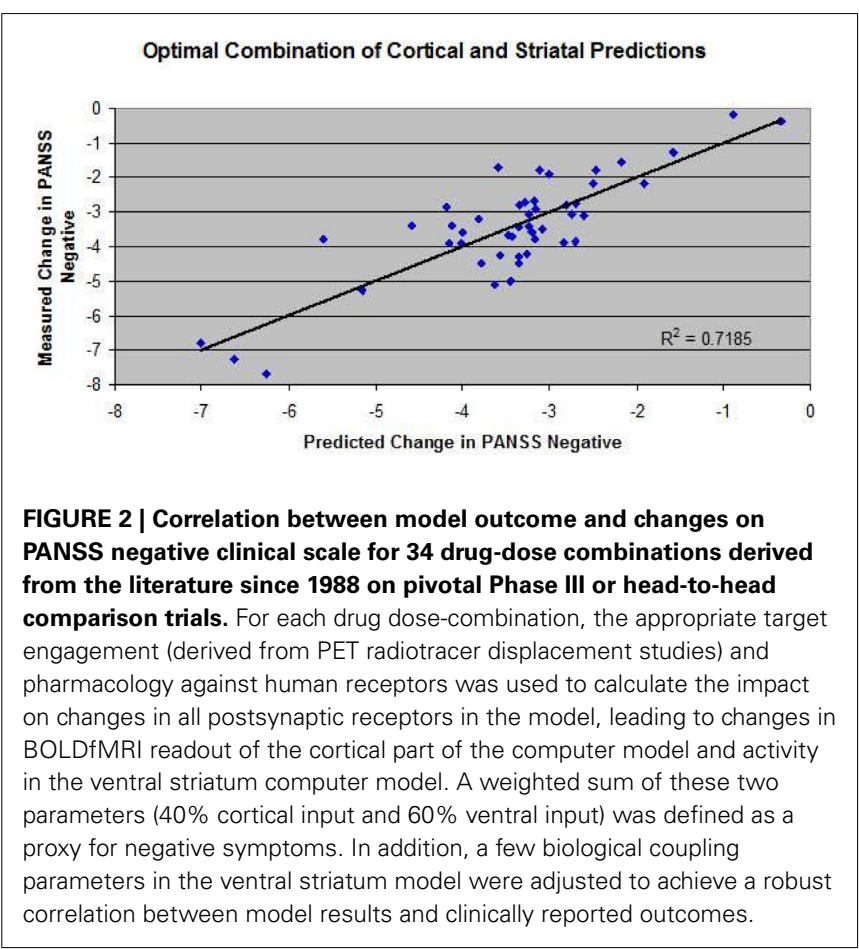



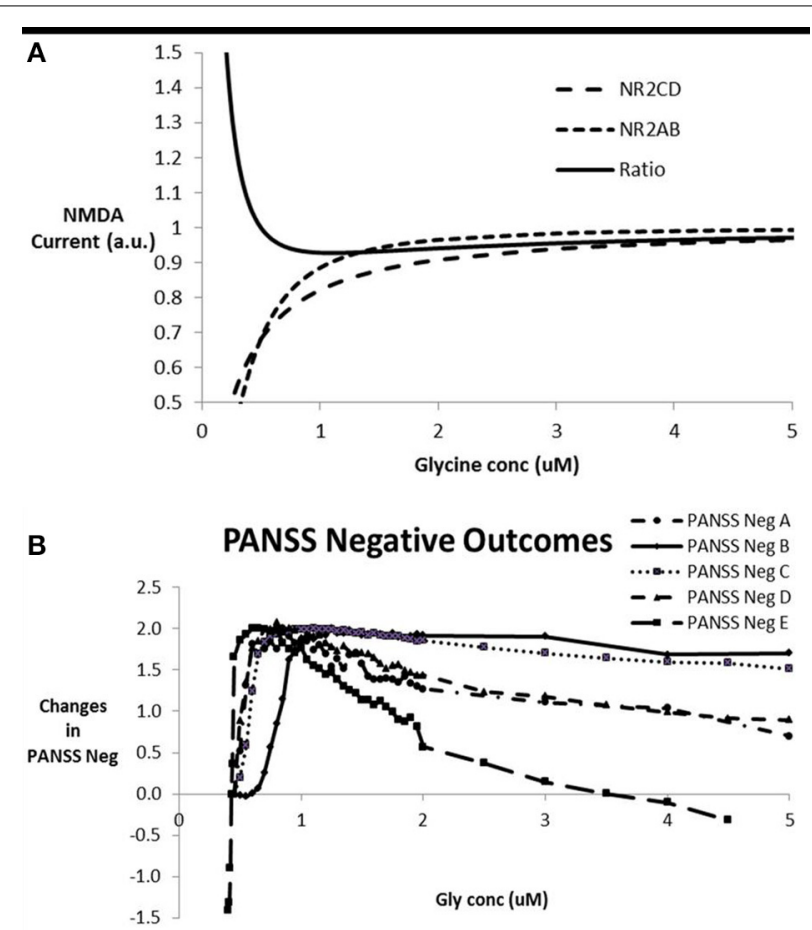

FIGURE 3 | (A) Relative currents through NMDA- NR $2 C / D$ subunits in pyramidal-inhibitory glutamatergic synapses (e-i) over NMDA currents and NMDA- $\mathrm{NR}_{2 \mathrm{~A} / \mathrm{B}}$ subunits in pyramidal-pyramidal glutamatergic synapses (e-e) and the ratio of $\mathrm{NR}_{2 \mathrm{C} / \mathrm{D}}$ over $\mathrm{NR}_{2 \mathrm{~A} / \mathrm{B}}$ currents as a function of glycine concentration. This particular graph corresponds to a value of 0.35 and $0.25 \mathrm{uM}$ for $\mathrm{EC}_{50}$ of $\mathrm{NR}_{2 \mathrm{~A} / \mathrm{B}}$ and $\mathrm{NR}_{2 \mathrm{C} / \mathrm{D}}$ respectively and a Hill coefficient of 1.84 and 1.1 for $N R_{2 A / B}$ and $N R_{2 C / D}$ respectively. This particular case shows a minimum of 0.93 on the ratio of $\mathrm{NR}_{2 C / D}$ over $\mathrm{NR}_{2 A / B}$ at a glycine concentration of $1.1 \mathrm{uM}$. For certain combinations of the $\mathrm{EC}_{50}$ and Hill coefficients of the interaction between glycine and its binding site on NMDA receptors, the ratio shows a U-shape dose-response. For glycine concentrations where the e-i over e-e ratio drops below 1 (in this case between 0.5 and $30 \mathrm{uM}$ ), this leads to a relative dominance of the excitatory tone over the inhibitory tone and a greater firing and BOLD-fMRI outcome. (B) Dose-response of the model outcome for negative symptoms as a function of glycine concentration for different combinations of parameters for glycine-NR $2 \mathrm{C} / \mathrm{D}$ vs. glycine- $\mathrm{NR}_{2 \mathrm{~A} / \mathrm{B}}$ interactions after calibration with clinical data. The parameter settings are $E_{50}$ for $N_{2 C / D}$, Hill coefficient for $\mathrm{NR}_{2 \mathrm{C} / \mathrm{D}}, \mathrm{EC}_{50}$ for $\mathrm{NR}_{2 \mathrm{~A} / \mathrm{B}}$, Hill coefficient for $\mathrm{NR}_{2 \mathrm{~A} / \mathrm{B} \text {, }}$ respectively so that the conditions shown are $A(0.2 \mathrm{uM}, 0.7,0.3 \mathrm{uM}, 1.7)$; $B$ (0.2 uM, 1, 0.22 uM, 1.5); C (0.21 uM, 1, 0.25 uM, 2); D (0.2 uM, 1, 0.35 uM, $2)$; and $\mathrm{E}(0.20 \mathrm{uM}, 1.46,0.35 \mathrm{uM}, 1.78)$. In a clinical trial, glycine concentration can be altered using either a glycine transporter inhibitor or substitution with glycine. Note the inverse U-shape dose-response that parallels the ratio of current through the NMDA-NR 2 subunits located at the excitatory-excitatory synapses over the current through the NMDA-NR 2 subunits located at the excitatory-inhibitory synapses. Maximal effect is in the two-point range but is only obtainable if the typical glycine concentration is around $1 \mathrm{uM}$. With higher glycine concentration, in many cases the effect decreases, with a worsening of negative symptoms in some cases for glycine concentrations greater than $5 \mathrm{uM}$.

(4-12 weeks) with outcomes on the PANSS negative subscale. Each of these drug-dose combinations was then first simulated with the appropriate PET tracer displacement (with ${ }^{11} \mathrm{C}$ raclopride) studies in the dopamine receptor competition model to yield the functional intrasynaptic drug concentration that corresponded to the observed tracer displacement. These functional drug doses were then applied to the receptor competition model for all postsynaptic receptors (other dopamine receptors, in addition to serotonergic, cholinergic, and norepinephrine receptors) in the computer model using the appropriate pharmacological interaction between that particular drug and the human receptor subtype. With the resulting changes in postsynaptic receptor activation for all synapses in the negative symptoms QSP computer model, in silico computer model results were obtained for each drug-dose combination, in particular changes in BOLDfMRI readout of the cortical part of the computer model and activity in the ventral striatum computer model. A weighted combination of these two parameters was then defined as a proxy for negative symptoms.

Those results were then compared to the corresponding actual clinical readouts on PANSS Negative. Figure 2 shows the correlation between the model outcome of these drug-dose combinations and the actual reported changes in PANSS Negative. A few biological coupling parameters in the ventral striatum model were adjusted to achieve a robust correlation. The observed correlation suggests that the model captures a substantial part of the variance.

\section{DOSE-RESPONSE OF GLYCINE MODULATION}

In order to simulate the effect of modulating glycine concentration on the network outcome, we proceeded by calculating the Hill equations for the interaction between glycine and the $\mathrm{NR}_{2}$ subunit on the excitatory-excitatory (e-e) glutamatergic synapses with NMDA subunits $\left(\mathrm{NR}_{2 \mathrm{~A}}-\mathrm{NR}_{2 \mathrm{~B}}\right)$ and the excitatory-inhibitory (e-i) glutamatergic synapses with NMDA subunits $\mathrm{NR}_{2 \mathrm{C}}-\mathrm{NR}_{2 \mathrm{D}}$. Figure 3A shows the currents through the two synapse types and their ratios as a function of glycine concentration. Due to the complex non-linear effects, for a number of $\mathrm{EC}_{50}$ and Hill coefficient parameter settings, the ratio of inhibitory to excitatory NMDA response decreases, reaches a minimum and then increases again, allowing for a complex non-monotonic doseresponse. The range of $\mathrm{EC}_{50}$ and Hill coefficient parameters for which this can be observed is examined in the following section.

When entering these changes for the effect of glycine on ee and e-i glutamatergic synapses as corresponding changes in NMDA maximum conductances on the respective synapses, the impact on the output of the network can be calculated. Figure 3B shows the anticipated clinical outcome on the PANSS negative scale based on the calibration (Figure 2) for a number of combinations of the interaction parameters between glycine and its binding site on the NMDA receptor. The clinical benefit follows an inverse $\mathrm{U}$-shape dose-response relationship with the free glycine concentration provided that the typical glycine concentrations are less than $0.5 \mathrm{uM}$, very similar to the dose-response of the ratio of the currents, $\mathrm{NR}_{2 \mathrm{C}} / 2 \mathrm{D}$ to $\mathrm{NR}_{2 \mathrm{~A}} /{ }_{2 \mathrm{~B}} \mathrm{NMDA}$ subtypes. In fact using a number of different values for the $\mathrm{EC}_{50}$ and Hill coefficient parameters, we can confirm the correspondence between these two dose-responses (data not shown).

Although the dose-responses in general are similar for the different glycine interaction parameters, the glycine concentration for which there is a clinical benefit varies substantially. As no experimental data are available for the interaction of glycine with 
the glycine binding site in the living human brain, in principle accordance between the model outcome and the clinical results will help to narrow down the range of likely parameters. In the following section we will address these issues in more detail.

\section{SENSITIVITY OF THE MODEL TO BIOLOGICAL COUPLING AND PHYSIOLOGY PARAMETERS}

We then studied the sensitivity of the model outcome as a function of small changes on all possible parameters, including the changes that reflect the implementation of the schizophrenia pathology. This could be envisaged as the intrinsic variability in a large set of patients possibly driven by the appearance of genotypic changes in neurophysiological and neuropathological pathways. For this we allowed the parameter to change by a certain fraction around their calibrated value. A general effect size is calculated by dividing the difference between the maximum and minimum relative effects by the fractional range in parameter settings. From the outcomes reported in Table 2, it is clear that the changes in pathology implementation at the level of the cortical network lead to the largest changes in the results. The effect of the parameters on the Hill equations for the interaction between glycine and its binding site on the NMDA-R will be explored in detail in the following section.

\section{SENSITIVITY ANALYSIS ON GLYCINE HILL EQUATION}

A crucial set of parameters is the relative values of the $\mathrm{EC}_{50}$ and Hill coefficients for the glycine-NMDA current effect through the

Table 2 | Sensitivity of the model outcome for different parameters and coupling constants that are changed between 20 and $50 \%$ in both directions for the glycine dose-response.

\begin{tabular}{lcccc}
\hline & $\begin{array}{c}\text { Sensitivity } \\
\text { range (\%) }\end{array}$ & $\begin{array}{c}\text { Minimal } \\
\text { effect (\%) }\end{array}$ & $\begin{array}{c}\text { Maximal } \\
\text { effect (\%) }\end{array}$ & $\begin{array}{c}\text { Effect } \\
\text { size }\end{array}$ \\
\hline INTERACTION GLYCINE & & & & \\
$\begin{array}{l}\text { EC50 on inhibitory } \\
\text { neurons }\end{array}$ & -50 to +50 & -18.6 & 20.7 & 0.393 \\
$\begin{array}{l}\text { Hill slope on inhibitory } \\
\text { neurons }\end{array}$ & +50 to -50 & -22.1 & 13.4 & 0.355 \\
$\begin{array}{l}\text { EC50 on excitatory } \\
\text { neurons }\end{array}$ & +50 to -50 & -14.1 & 38.9 & 0.530 \\
Hill slope on excitatory & -50 to +50 & -18.4 & 14.3 & 0.327 \\
neurons & & & & \\
CORTICAL SZ PATHOLOGY & +20 to -20 & -37.7 & 18.2 & 1.398 \\
NMDA reduction & -10 to +10 & -32.4 & 20.8 & 1.620 \\
$\begin{array}{l}\text { GABA reduction } \\
\text { DA deficit }\end{array}$ & -41 to +41 & -7.9 & 2.8 & 0.130 \\
Noise increase & +24 to -24 & -13.9 & 18.5 & 0.675 \\
STRIATAL PHYSIOLOGY & & & & \\
\hline $\begin{array}{l}\text { DA receptors } \\
\text { Muscarinic receptors }\end{array}$ & +20 to -20 & -9.3 & 10.1 & 0.485 \\
\hline
\end{tabular}

Maximal and minimal effect on the dose-response are derived. The general effect size is calculated as the difference between maximal and minimal outcome divided by the input range. The data suggest that GABA and NMDA reduction have a big impact on the outcome, likely because they are driving the baseline excitation-inhibition balance upon which glycine modulation will act. different NR2 subunits. As shown in the previous section, the inverse U-shape dose-response in the cortical network outcome corresponding to a clinical benefit on PANSS negative is associated with a U-shape dose-response of the ratio of inhibitory over excitatory effect (compare Figure 3A with Figure 3B). Note that the glycine concentration for maximal effect on the network corresponds to the glycine concentration of the minimum in the ratio of $\mathrm{NR}_{2 \mathrm{C} / \mathrm{D}}$ over $\mathrm{NR}_{2 \mathrm{~A} / \mathrm{B}}$.

Because the experimentally determined values reported in Table 1 for the interaction of glycine with the human NMDA NR 2 subunits were performed in an artificial in vitro system and could be quite different from the actual human in vivo situation, we systematically studied the effect of changing the values for $\mathrm{EC}_{50}$ on the network outcome.

Figure 4 shows the sensitivity analysis when probing different parameter ranges for $\mathrm{EC}_{50}$ and Hill coefficients of the interaction between glycine and the NMDA-NR2 subunits. It is clear that higher Hill coefficients for the $\mathrm{NR}_{2 \mathrm{~A}} / \mathrm{B}$ subunits compared to the $\mathrm{NR}_{2 \mathrm{C}} / \mathrm{D}$ subunits is necessary for a beneficial effect on the network outcome with the range increasing with larger differences between the Hill coefficients for $\mathrm{NR}_{2 \mathrm{~A}} / 2 \mathrm{~B}$ vs. $\mathrm{NR}_{2} \mathrm{C} / 2 \mathrm{D}$ subunits.

\section{PHYSIOLOGICAL RANGE OF GLYCINE CONCENTRATION}

The free glycine concentration in the human brain is regulated by a $2 \mathrm{Na}^{+}-\mathrm{Cl}^{-}$-Gly co-transporter system and its value is constrained by the Nernst-Goldman equation. Therefore, the functional free glycine concentrations in steady-state equilibrium conditions is dependent upon the range of concentrations for intracellular and extracellular $\mathrm{Na}^{+}$and $\mathrm{Cl}^{-}$. Assuming the glycine transporter is located on astrocytes, all calculations are done for astrocyte membrane potential and intracellular ion concentrations. Astrocyte membrane potential, while not changing on the same time scale as neuronal membrane potential is supposed to be in the -50 to $-70 \mathrm{mV}$ range for steady state conditions.

With the exception of extreme pathological situations such as in stroke or neurotrauma, $\mathrm{Na}^{+}$and $\mathrm{Cl}^{-}$ion concentrations in the human brain are tightly regulated. Figure 5 shows a number of solutions to the Nernst-Goldman equation for different ranges of intracellular $\mathrm{Na}^{+}$and intracellular glycine concentrations. All figures are derived for constant values of intracellular $\mathrm{Cl}^{-}$of $6 \mathrm{mM}$ and extracellular $\mathrm{Cl}^{-}$concentration of $120 \mathrm{mM}$. It is clear that in the absence of extreme pathology, the range of free extracellular glycine is limited and is unlikely to exceed $10 \mathrm{uM}$.

\section{INTERNALIZATION OF NMDA-R AT HIGH GLYCINE CONCENTRATIONS}

High glycine exposure in principle could overstimulate the NMDA-R and lead to epileptic seizures. In preclinical slice work, NMDA-R internalization has been observed at very high glycine concentrations, typically with an EC50 value in the range of $40 \mathrm{uM}$ (Nong et al., 2003). While the Nernst-Goldman equations that regulate the free glycine concentration as a function of free $\mathrm{Na}$ and $\mathrm{Cl}$ strongly suggest that glycine concentrations beyond $5 \mathrm{uM}$ are highly unlikely (see Figure 5), we nevertheless simulated the effect of NMDA-NR 2 subunit internalization on the computer model outcome. 


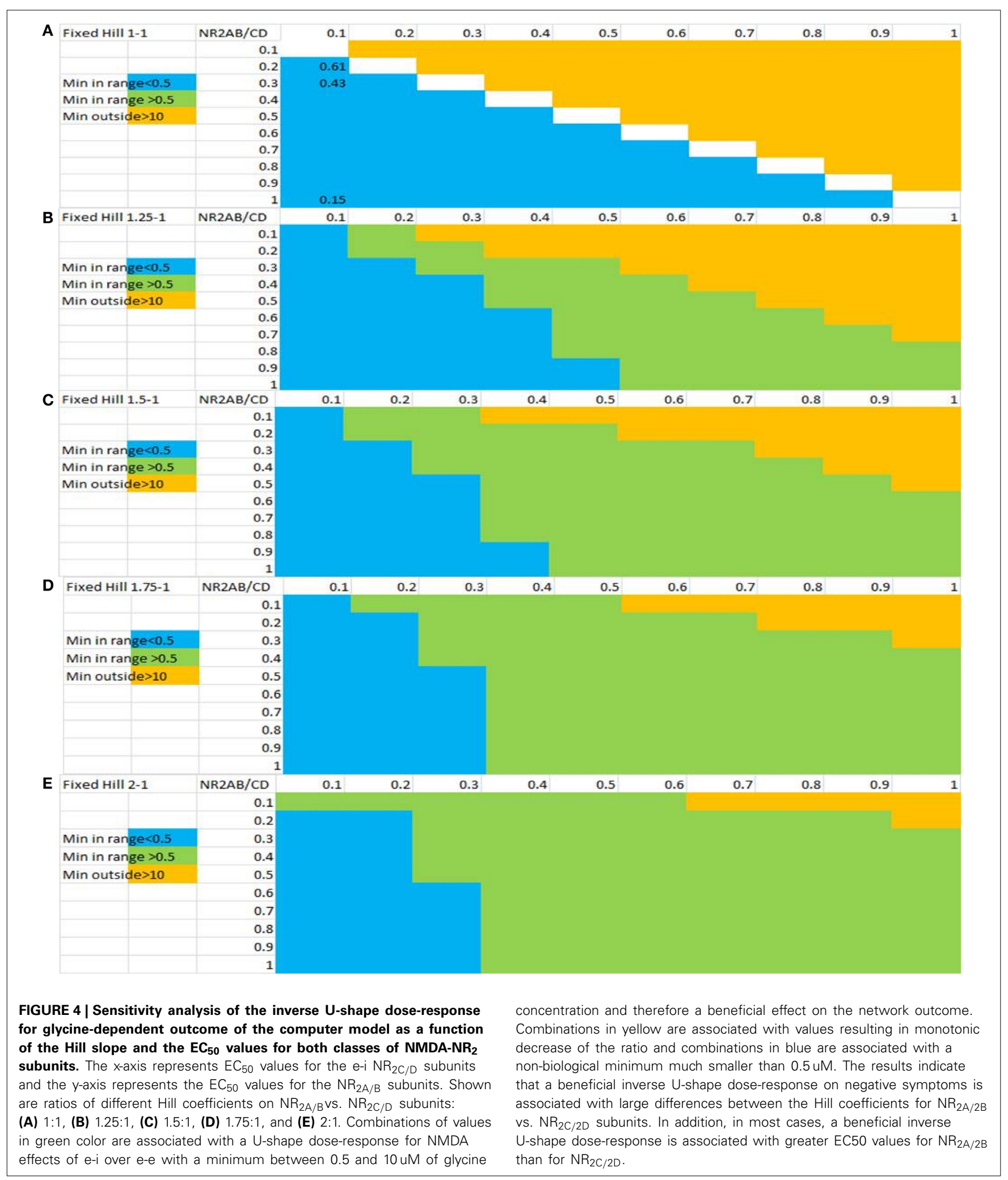

We simulated two conditions of internalization (Figure 6). The first condition assumes the same $\mathrm{EC}_{50}$ value $(40 \mathrm{uM})$ for both $\mathrm{NR}_{2 \mathrm{~A}} / \mathrm{B}$ subunits as for NR2C/D subunits. As expected, for very low levels of glycine where the internalization process has a very limited effect, the dose-response shows a peak for glycine levels in the low uM range. The results further suggest that internalization of the NMDA-R assuming the same $\mathrm{EC}_{50}$ values for the two types of $\mathrm{NR}_{2}$ subunits leads to a substantial decrease (corresponding 


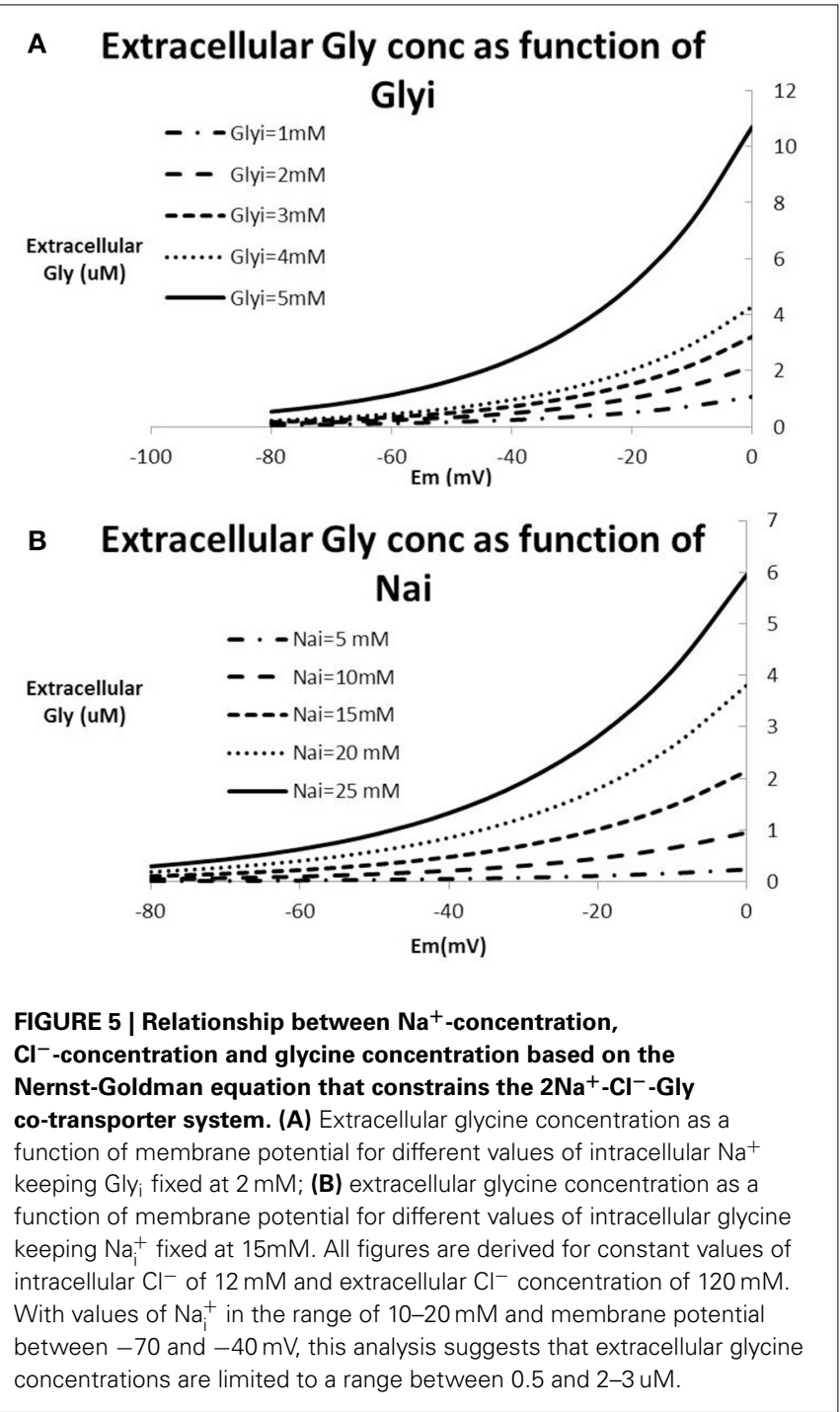

to a collapse of network activity at glycine levels beyond $20 \mathrm{uM}$ ). The second assumption assumes that the internalization process would have the same affinity as glycine itself, i.e., an $\mathrm{EC}_{50}$ of $32 \mathrm{uM}$ for the $\mathrm{NR}_{2 \mathrm{~A}} / \mathrm{B}$ subunits and an $\mathrm{EC}_{50}$ of $50 \mathrm{uM}$ for the $\mathrm{NR}_{2 \mathrm{C}}$ /D subunits. In that case, the simulations suggest that the model outcome first improves beyond the no internalization case before collapsing at glycine levels beyond $40 \mathrm{uM}$.

\section{DISCUSSION}

This report describes a quantitative systems pharmacology computer model based on physiologically realistic interactions in models of a cortical network and the ventral striatum. The major result of this simulation is the prediction of an inverse U-shape dose-response with glycine that is a consequence of the shifting balance between excitation and inhibition in the cortical network, secondary to an interesting difference in pharmacological properties of glycine for the different NMDA subunits regulating excitatory and inhibitory tone.

The sensitivity analysis suggests that there are a substantial number of parameter combinations that result in such an inverse

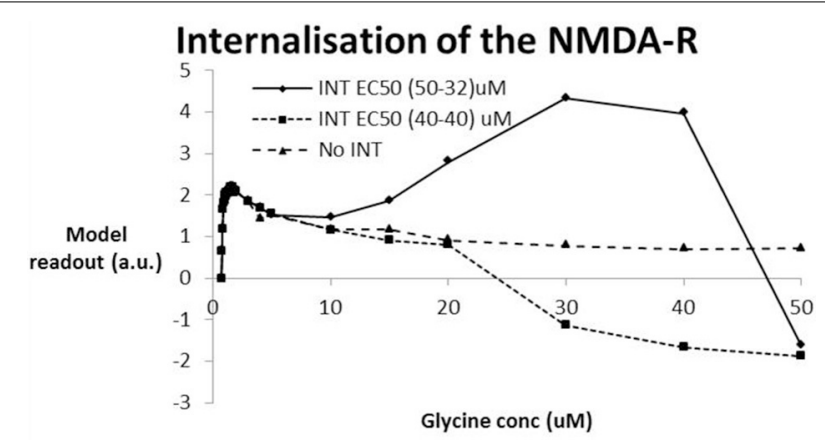

FIGURE 6 | Effect of NMDA-R internalization under the hypothesis that high levels of glycine are possible and using the experimental data from (Nong et al., 2003). Two conditions of internalization are simulated: INT-1-EC 50 (40-40) assumes the same $\mathrm{EC}_{50}$ for internalization of $\mathrm{NR}_{2 \mathrm{~A} / \mathrm{B}}$ subunits as for $\mathrm{NR}_{2 \mathrm{C} / \mathrm{D}}$ subunits $(40 \mathrm{uM})$; INT-2-EC 50 (50-32) assumes the $E_{50}$ for internalization of the $N_{2 C / D}$ is lower $(32 \mathrm{uM})$ than for the $N R_{2 A / B}$ subunit $(50 \mathrm{uM})$ in accordance with the relative difference in $\mathrm{EC}_{50}$ for glycine to the glycine binding site. INT-1 is similar to the situation without internalization reaching a peak for glycine levels in the low uM until the network starts to collapse around a value of $20 \mathrm{uM}$. With INT-2, the model outcome reaches a similar early peak for glycine levels in the low uM that drops off before it begins to improve (at $10 \mathrm{uM}$ ) before collapsing at a glycine level beyond $40 \mathrm{uM}$.

U-shape dose-response with glycine. The exact values for the interaction in the human brain is unknown and probably is different for each subject, but in general an inverse U-shape dose-response can be achieved when both the $\mathrm{EC}_{50}$ and the Hill coefficient for the glycine effect on the $\mathrm{NR}_{2 C / D}$ subunit is lower than for the $\mathrm{NR}_{2 \mathrm{~A} / \mathrm{B}}$ subunit. It is of interest to note from different experimental data that on average the interaction of glycine with the NMDA-NR $2 \mathrm{~B}$ subunit indeed suggests a higher value for the Hill coefficient. As noted in the Biological Introduction, the neurodevelopmental trajectory of schizophrenia tends to delay the appearance of the mature NMDA-NR $2 \mathrm{~A}$ subunit, so that there is a relatively higher contribution of the NMDA-NR $2 \mathrm{~B}$ subunit to the excitatory tone in schizophrenics. This allows the interaction of glycine with the e-e NMDA receptor to have a higher Hill slope in combination with a lower $\mathrm{EC}_{50}$ concentration, promoting an inverse U-shape dose-response.

The clinical Phase II data with the glycine inhibitor bitopertin suggest indeed that the clinical outcome follows such as doseresponse. Some studies with $\mathrm{D}$-serine, $\mathrm{D}$-sarcosine or glycine have often reported mixed effects (Singh and Singh, 2011), with some but not all showing a clinical benefit and the interpretation is hampered by the lack of data on proper target engagement. It is conceivable that this could be a consequence of the nonlinear dose-response with patients on different points of the dose-response. It is also of interest to note that negative symptoms seem to be most improved when glycine or D-serine levels are increased (Singh and Singh, 2011). The QSP platform when calibrated suggests a rather limited effect of glycine modulation on clinical changes in PANSS negative in the range of 2-2.5 points. Note that the patient population used for calibration was not selected for extremely high negative symptomatology, resulting in a baseline PANSS negative between 18 and 24. Although 
this observed change is in line with published data on glutamatergic modulation (Singh and Singh, 2011), it suggests that such a limited effect might be difficult to be detected in clinical situations.

These results also lead to the important observation that because of the different contribution of the NMDA-NR2 subunits, the interaction between glycine and the NMDA receptors likely is different in healthy volunteers as compared with schizophrenia patients. Such a difference is extremely difficult to achieve in preclinical animal models. Therefore, great care needs to be taken to extrapolate positive or negative findings from a Phase I proof-of-concept study in healthy volunteers to actual schizophrenia patients.

Similarly, rodent models often lack the right mix of NMDA receptor subtypes to simulate very well the actual pathology mediated and often do not show the inverse U-shape doseresponse (Alberati et al., 2011). Not realizing this could substantially hamper the clinical development and often can lead to failed clinical trials. In addition, clinical trials have been performed as augmentation strategy, i.e., the glycine modulator intervention is given to patients on stable antipsychotic medication. Such comedications can have a direct effect through affecting the metabolism of the active compound which is dependent upon the genotype of the specific Cytochrome P450 enzyme but can also be modified by other comedications such as nicotine (Tsuda et al., 2014). The comedications can also have an indirect effect on the dose-response of glycine level modulation through non-linear interactions on the excitation-inhibition balance that affect the emergent properties such as the BOLD-fMRI signal. This paper does not address the issue of comedication, but we are planning to perform such an in-depth analysis in a follow-up paper.

\section{LIMITATIONS OF THE MODEL}

Firstly, different reports suggest that D-serine plays a more important role as co-agonist on the NMDA-R in the cortex (Fossat et al., 2012) while other studies suggest a role for both D-serine and glycine in regulating neuronal morphology in rodent somatosensory cortex (Balu et al., 2012). To a certain extent, the interaction of D-serine with the co-agonist site on the NMDA-R is quite similar to glycine's interaction (Chen et al., 2008), but the level of free $\mathrm{D}$-serine is regulated by serine racemase localized in neurons (Balu et al., 2014) and by a $\mathrm{Na}^{+}$-independent alanine-cysteineserine transporter system (Maucler et al., 2013). This suggests that most of the conclusions for glycine, with the exception of the limited range of glycine driven by its specific $\mathrm{Na}^{+}$-dependent co-transporter system can be applied to the modulation of D-serine.

There is also some discussion about the nature of the NMDA $\mathrm{NR}_{2}$ subunits on the inhibitory cell types in cortical networks. mRNA studies in the human brain localize the $\mathrm{NR}_{2} \mathrm{C}$ subunit predominantly to the cerebellum (Monyer et al., 1992) although there are lower levels present in the cortex (Allen Brain institute data http://human.brain-map.org/). However, $\mathrm{NR}_{2 \mathrm{D}}$ subunits are likely present in cortical areas on excitatory-inhibitory synapses and could play a predominant role in the generation of the inhibitory tone. The exact interaction parameters between glycine and its co-agonist binding site on the NMDA receptor in the human brain are unknown, but the computer model suggests a range of interaction parameters that would correspond to an inverse U-shape dose-response. Although adding a greater contribution of $\mathrm{NR}_{2 \mathrm{D}}$ to the inhibitory tone will increase the $\mathrm{EC}_{50}$ of the e-i interaction, it will also decrease the Hill coefficient as compared to the interaction of glycine with the e-e synapses, which has been shown to be favorable for an inverse U-shape dose-response.

The model presented here does not address the other modulatory agents such as extracellular proteins, zinc, polyamines, and neurosteroids. All these molecules can influence the dynamics of glycine-mediated amplification of NMDA-currents and we assumed that these modulators do not change in schizophrenia. In principle, if new data become available suggesting a change in these neuromodulators as a consequence of schizophrenia pathology, detailed biochemical data could be incorporated in this platform to estimate their impact.

In summary, this report simulates the anticipated doseresponse of glycine level modulation on an emergent property (BOLD-fMRI) of a computer-based neuronal circuit that has been calibrated against clinical outcomes for negative symptoms. It provides a physiological explanation for the appearance of an inverse U-shape dose-response based on a biologically constrained set of interaction parameters between glycine and the co-agonist site on different types of $\mathrm{NMDA}-\mathrm{NR}_{2}$ subunits and the electrogenic character of the $\mathrm{Gly} / 2 \mathrm{Na} / \mathrm{Cl}$ co-transport system. A notable limitation is that this study deals with the effect of glycine modulation in the absence of any antipsychotic medication and therefore does not reflect the real clinical study design.

\section{REFERENCES}

Abdallah, L., Bonasera, S. J., Hopf, F. W., O’Dell, L., Giorgetti, M., Jongsma, M., et al. (2009). Impact of serotonin 2C receptor null mutation on physiology and behavior associated with nigrostriatal dopamine pathway function. J. Neurosci. 29, 8156-8165. doi: 10.1523/JNEUROSCI.390508.2009

Alberati, D., Moreau, J. L., Lengyel, J., Hauser, N., Mory, R., Borroni, E., et al. (2011). Glycine reuptake inhibitor RG1678: a pharmacologic characterization of an investigational agent for the treatment of schizophrenia. Neuropharmacology 62, 1152-1161. doi: 10.1016/j.neuropharm.2011.11.008

Aroniadou-Anderjaska, V., Qashu, F., and Braga, M. F. (2007). Mechanisms regulating GABAergic inhibitory transmission in the basolateral amygdala: implications for epilepsy and anxiety disorders. Amino Acids 32, 305-315. doi: 10.1007/s00726-006-0415-x

Balu, D. T., Basu, A. C., Corradi, J. P., Cacace, A. M., and Coyle, J. T. (2012). The NMDA receptor co-agonists, D-serine and glycine, regulate neuronal dendritic architecture in the somatosensory cortex. Neurobiol. Dis. 45, 671-682. doi: 10.1016/j.nbd.2011.10.006

Balu, D. T., Takagi, S., Puhl, M. D., Benneyworth, M. A., and Coyle, J. T. (2014). $\mathrm{D}$-serine and serine racemase are localized to neurons in the adult mouse and human forebrain. Cell. Mol. Neurobiol. 34, 419-435. doi: 10.1007/s10571-0140027-z

Bamford, N. S., Robinson, S., Palmiter, R. D., Joyce, J. A., Moore, C., and Meshul, C. K. (2004). Dopamine modulates release from corticostriatal terminals. J. Neurosci. 24, 9541-9552. doi: 10.1523/JNEUROSCI.2891-04.2004

Braga, M. F., Aroniadou-Anderjaska, V., Manion, S. T., Hough, C. J., and Li, H. (2004). Stress impairs alpha(1A) adrenoceptor-mediated noradrenergic facilitation of GABAergic transmission in the basolateral amygdala. Neuropsychopharmacology 29, 45-58. doi: 10.1038/sj.npp.13 00297

Buxton, R. B. (2012). Dynamic models of BOLD contrast. Neuroimage 62, 953-961. doi: 10.1016/j.neuroimage.2012.01.012 
Buxton, R. B., Uludag, K., Dubowitz, D. J., and Liu, T. T. (2004). Modeling the hemodynamic response to brain activation. Neuroimage, 23 Suppl 1, S220-S233. doi: 10.1016/j.neuroimage.2004. 07.013

Calabresi, P., Centonze, D., Gubellini, P., Pisani, A., and Bernardi, G. (1998). Endogenous ACh enhances striatal NMDA-responses via M1-like muscarinic receptors and PKC activation. Eur. J. Neurosci. 10, 2887-2895. doi 10.1111/j.1460-9568.1998.00294.x

Chen, P. E., Geballe, M. T., Katz, E., Erreger, K., Livesey, M. R., O’Toole, K. K., et al. (2008). Modulation of glycine potency in rat recombinant NMDA receptors containing chimeric NR2A/2D subunits expressed in Xenopus laevis oocytes. J. Physiol. 586, 227-245. doi: 10.1113/jphysiol.2007.143172

Cherubino, F., Bossi, E., Miszner, A., Ghezzi, C., and Peres, A. (2010). Transient currents in the glycine cotransporter GlyT1 reveal different steps in transport mechanism. J. Mol. Neurosci. 41, 243-251. doi: 10.1007/s12031-009-9281-9

Coyle, J. T. (2006). Glutamate and schizophrenia: beyond the dopamine hypothesis. Cell. Mol. Neurobiol. 26, 365-384. doi: 10.1007/s10571-006-9062-8

Cragg, S. J., Hille, C. J., and Greenfield, S. A. (2000). Dopamine release and uptake dynamics within nonhuman primate striatum in vitro. J. Neurosci. 20 8209-8217.

De Deurwaerdere, P., Stinus, L., and Spampinato, U. (1998). Opposite change of in vivo dopamine release in the rat nucleus accumbens and striatum that follows electrical stimulation of dorsal raphe nucleus: role of 5-HT3 receptors. I. Neurosci. 18, 6528-6538.

D'Souza, D. C., Singh, N., Elander, J., Carbuto, M., Pittman, B., de Haes, U., et al. (2012). Glycine transporter inhibitor attenuates the psychotomimetic effects of ketamine in healthy males: preliminary evidence. Neuropsychopharmacology 37, 1036-1046. doi: 10.1038/npp.2011.295

Eddins, D., Hamill, T. G., Puri, V., Cannon, C. E., Vivian, J. A., Sanabria-Bohorquez, S. M., et al. (2014). The relationship between glycine transporter 1 occupancy and the effects of the glycine transporter 1 inhibitor RG1678 or ORG25935 on object retrieval performance in scopolamine impaired rhesus monkey. Psychopharmacology (Berl.) 231, 511-519. doi: 10.1007/s00213-013-3260-0

Falk, T., Xie, J. Y., Zhang, S., Kennedy, J., Bennett, J., Yool, A. J., et al. (2008). Over-expression of the potassium channel Kir2.3 using the dopamine-1 receptor promoter selectively inhibits striatal neurons. Neuroscience 155, 114-127. doi: $10.1016 /$ j.neuroscience.2008.04.075

Falk, T., Zhang, S., Erbe, E. L., and Sherman, S. J. (2006). Neurochemical and electrophysiological characteristics of rat striatal neurons in primary culture. J. Comp. Neurol. 494, 275-289. doi: 10.1002/cne.20819

Fossat, P., Turpin, F. R., Sacchi, S., Dulong, J., Shi, T., Rivet, J. M., et al. (2012). Glial D-serine gates NMDA receptors at excitatory synapses in prefrontal cortex. Cereb. Cortex 22, 595-606. doi: 10.1093/cercor/bhr130

Funk, A. J., McCullumsmith, R. E., Haroutunian, V., and Meador-Woodruff, J. H. (2012). Abnormal activity of the MAPK- and cAMP-associated signaling pathways in frontal cortical areas in postmortem brain in schizophrenia. Neuropsychopharmacology 37, 896-905. doi: 10.1038/npp.2011.267

Geerts, H., Roberts, P., and Spiros, A. (2013a). A quantitative system pharmacology computer model for cognitive deficits in schizophrenia. CPT Pharmacometrics Syst. Pharmacol. 2, e36. doi: 10.1038/psp.2013.12

Geerts, H., Spiros, A., Roberts, P., and Carr, R. (2013b). Quantitative systems pharmacology as an extension of PK/PD modeling in CNS research and development. J. Pharmacokinet. Pharmacodyn. 40, 257-265. doi: 10.1007/s10928013-9297-1

Geerts, H., Spiros, A., Roberts, P., Twyman, R., Alphs, L., and Grace, A. A. (2012). Blinded prospective evaluation of computer-based mechanistic schizophrenia disease model for predicting drug response. PLoS ONE 7:e49732. doi: 10.1371/journal.pone.0049732

Goghari, V. M., Sponheim, S. R., and MacDonald, A. W. 3rd. (2010). The functional neuroanatomy of symptom dimensions in schizophrenia: a qualitative and quantitative review of a persistent question. Neurosci. Biobehav. Rev. 34 468-486. doi: 10.1016/j.neubiorev.2009.09.004

Gonzalez-Burgos, G., Hashimoto, T., and Lewis, D. A. (2010). Alterations of cortical GABA neurons and network oscillations in schizophrenia. Curr. Psychiatry Rep. 12, 335-344. doi: 10.1007/s11920-010-0124-8

Gruber, A. J., Solla, S. A., Surmeier, D. J., and Houk, J. C. (2003). Modulation of striatal single units by expected reward: a spiny neuron model displaying dopamine-induced bistability. J. Neurophysiol. 90, 1095-1114. doi: $10.1152 /$ jn. 00618.2002
Harvey, P. O., Armony, J., Malla, A., and Lepage, M. (2010). Functional neural substrates of self-reported physical anhedonia in non-clinical individuals and in patients with schizophrenia. J. Psychiatr. Res. 44, 707-716. doi: 10.1016/j.jpsychires.2009.12.008

Hay, M., Thomas, D. W., Craighead, J. L., Economides, C., and Rosenthal, J. (2014). Clinical development success rates for investigational drugs. Nat. Biotechnol. 32, 40-51. doi: 10.1038/nbt.2786

Hernandez-Echeagaray, E., Galarraga, E., and Bargas, J. (1998). 3-Alpha-chloroimperialine, a potent blocker of cholinergic presynaptic modulation of glutamatergic afferents in the rat neostriatum. Neuropharmacology 37, 1493-1502. doi: 10.1016/S0028-3908(98)00131-2

Hernandez-Lopez, S., Tkatch, T., Perez-Garci, E., Galarraga, E., Bargas, J., Hamm, H., et al. (2000). D2 dopamine receptors in striatal medium spiny neurons reduce L-type $\mathrm{Ca} 2+$ currents and excitability via a novel PLC[beta]1-IP3-calcineurin-signaling cascade. J. Neurosci. 20, 8987-8995.

Hersch, S. M., Gutekunst, C. A., Rees, H. D., Heilman, C. J., and Levey, A. I. (1994). Distribution of m1-m4 muscarinic receptor proteins in the rat striatum: light and electron microscopic immunocytochemistry using subtype-specific antibodies. J. Neurosci. 14(5 Pt 2), 3351-3363.

Hines, M. L., and Carnevale, N. T. (1997). The NEURON simulation environment. Neural Comput. 9, 1179-1209. doi: 10.1162/neco.1997.9.6.1179

Hokyo, A., Kanazawa, T., Uenishi, H., Tsutsumi, A., Kawashige, S., Kikuyama, H., et al. (2010). Habituation in prepulse inhibition is affected by a polymorphism on the NMDA receptor 2B subunit gene (GRIN2B). Psychiatr. Genet. 20, 191-198. doi: 10.1097/YPG.0b013e32833a201d

Horan, W. P., Kring, A. M., Gur, R. E., Reise, S. P., and Blanchard, J. J. (2011). Development and psychometric validation of the clinical assessment interview for negative symptoms (CAINS). Schizophr. Res. 132, 140-145. doi: 10.1016/j.schres.2011.06.030

Hyman, S. E. (2014). Revitalizing psychiatric therapeutics. Neuropsychopharmaco$\log y$ 39, 220-229. doi: 10.1038/npp.2013.181

Jiang, X., Knox, R., Pathipati, P., and Ferriero, D. (2011). Developmental localization of NMDA receptors, Src and MAP kinases in mouse brain. Neurosci. Lett. 503, 215-219. doi: 10.1016/j.neulet.2011.08.039

Juckel, G., Schlagenhauf, F., Koslowski, M., Filonov, D., Wustenberg, T., Villringer, A., et al. (2006a). Dysfunction of ventral striatal reward prediction in schizophrenic patients treated with typical, not atypical, neuroleptics. Psychopharmacology (Berl.) 187, 222-228. doi: 10.1007/s00213-006-0405-4

Juckel, G., Schlagenhauf, F., Koslowski, M., Wustenberg, T., Villringer, A., Knutson, B., et al. (2006b). Dysfunction of ventral striatal reward prediction in schizophrenia. Neuroimage 29, 409-416. doi: 10.1016/j.neuroimage.2005. 07.051

Kristiansen, L. V., Bakir, B., Haroutunian, V., and Meador-Woodruff, J. H. (2010a). Expression of the NR2B-NMDA receptor trafficking complex in prefrontal cortex from a group of elderly patients with schizophrenia. Schizophr. Res. 119, 198-209. doi: 10.1016/j.schres.2010.02.1069

Kristiansen, L. V., Patel, S. A., Haroutunian, V., and Meador-Woodruff, J. H. (2010b). Expression of the NR2B-NMDA receptor subunit and its Tbr-1/CINAP regulatory proteins in postmortem brain suggest altered receptor processing in schizophrenia. Synapse 64, 495-502. doi: 10.1002/syn.20754

Kutsuwada, T., Kashiwabuchi, N., Mori, H., Sakimura, K., Kushiya, E., Araki, K., et al. (1992). Molecular diversity of the NMDA receptor channel. Nature 358, 36-41. doi: 10.1038/358036a0

Kuzhikandathil, E. V., and Oxford, G. S. (2002). Classic D1 dopamine receptor antagonist $\mathrm{R}$-(+)-7-chloro-8-hydroxy-3-methyl-1-phenyl-2,3,4,5tetrahydro-1H-3-benzaze pine hydrochloride (SCH23390) directly inhibits G protein-coupled inwardly rectifying potassium channels. Mol. Pharmacol. 62, 119-126. doi: 10.1124/mol.62.1.119

Laurie, D. J., and Seeburg, P. H. (1994). Ligand affinities at recombinant N-methylD-aspartate receptors depend on subunit composition. Eur. J. Pharmacol. 268, 335-345. doi: 10.1016/0922-4106(94)90058-2

Law-Tho, D., Hirsch, J. C., and Crepel, F. (1994). Dopamine modulation of synaptic transmission in rat prefrontal cortex: an in vitro electrophysiological study. Neurosci. Res. 21, 151-160. doi: 10.1016/0168-0102(94)90157-0

Li, S., Cao, J., Yang, X., Suo, Z. W., Shi, L., Liu, Y. N., et al. (2011). NR2B phosphorylation at tyrosine 1472 in spinal dorsal horn contributed to $\mathrm{N}$ methyl-D-aspartate-induced pain hypersensitivity in mice. J. Neurosci. Res. 89, 1869-1876. doi: 10.1002/jnr.22719 
Liem-Moolenaar, M., Zoethout, R., de Boer, P., Schmidt, M., de Kam, M., Cohen, A., et al. (2010). The effects of the glycine reuptake inhibitor R213129 on the central nervous system and on scopolamine-induced impairments in psychomotor and cognitive function in healthy subjects. J. Psychopharmacol. 24, 1671-1679. doi: 10.1177/0269881109106942

Ma, B., Xu, G., Wang, W., Enyeart, J. J., and Zhou, M. (2014). Dual patch voltage clamp study of low membrane resistance astrocytes in situ. Mol. Brain 7, 18. doi: 10.1186/1756-6606-7-18

Malenka, R. C., and Kocsis, J. D. (1988). Presynaptic actions of carbachol and adenosine on corticostriatal synaptic transmission studied in vitro. J. Neurosci. $8,3750-3756$

Matsui, T., Sekiguchi, M., Hashimoto, A., Tomita, U., Nishikawa, T., and Wada, K. (1995). Functional comparison of D-serine and glycine in rodents: the effect on cloned NMDA receptors and the extracellular concentration. J. Neurochem. 65 , 454-458. doi: 10.1046/j.1471-4159.1995.65010454.x

Maucler, C., Pernot, P., Vasylieva, N., Pollegioni, L., and Marinesco, S. (2013). In vivo $\mathrm{D}$-serine hetero-exchange through alanine-serine-cysteine (ASC) transporters detected by microelectrode biosensors. ACS Chem. Neurosci. 4, 772-781. doi: $10.1021 / \mathrm{cn} 4000549$

Menon, V., Anagnoson, R. T., Glover, G. H., and Pfefferbaum, A. (2001). Functional magnetic resonance imaging evidence for disrupted basal ganglia function in schizophrenia. Am. J. Psychiatry 158, 646-649. doi: 10.1176/appi.ajp.158.4.646

Mermelstein, P. G., Song, W. J., Tkatch, T., Yan, Z., and Surmeier, D. J. (1998). Inwardly rectifying potassium (IRK) currents are correlated with IRK subunit expression in rat nucleus accumbens medium spiny neurons. J. Neurosci. 18 , 6650-6661.

Meyer-Lindenberg, A., Miletich, R. S., Kohn, P. D., Esposito, G., Carson, R. E., Quarantelli, M., et al. (2002). Reduced prefrontal activity predicts exaggerated striatal dopaminergic function in schizophrenia. Nat. Neurosci. 5, 267-271. doi: $10.1038 / \mathrm{nn} 804$

Mingoia, G., Wagner, G., Langbein, K., Maitra, R., Smesny, S., Dietzek, M. et al. (2012). Default mode network activity in schizophrenia studied at resting state using probabilistic ICA. Schizophr. Res. 138, 143-149. doi: 10.1016/j.schres.2012.01.036

Monyer, H., Burnashev, N., Laurie, D. J., Sakmann, B., and Seeburg, P. H. (1994). Developmental and regional expression in the rat brain and functional properties of four NMDA receptors. Neuron 12, 529-540. doi: 10.1016/08966273(94)90210-0

Monyer, H., Sprengel, R., Schoepfer, R., Herb, A., Higuchi, M., Lomeli, H., et al. (1992). Heteromeric NMDA receptors: molecular and functional distinction of subtypes. Science 256, 1217-1221. doi: 10.1126/science.256.5060.1217

Nicholas, T., Duvvuri, S., Leurent, C., Raunig, D., Rapp, T., Iredale, P., et al. (2013). Systems pharmacology modeling in neuroscience: prediction and outcome of PF-04995274, a 5HT4 partial agonist, in a clinical scopolamine impairment trial. Adv. Alzheimers Dis. 2, 83-98. doi: 10.4236/aad.2013.23012

Nong, Y., Huang, Y. Q., Ju, W., Kalia, L. V., Ahmadian, G., Wang, Y. T., et al. (2003). Glycine binding primes NMDA receptor internalization. Nature 422, 302-307. doi: 10.1038/nature01497

O'Donnell, P., and Grace, A. A. (1994). Tonic D2-mediated attenuation of cortical excitation in nucleus accumbens neurons recorded in vitro. Brain Res. 634 105-112. doi: 10.1016/0006-8993(94)90263-1

Okamoto, M., Akanuma, S., Tachikawa, M., and Hosoya, K. (2009). Characteristics of glycine transport across the inner blood-retinal barrier. Neurochem. Int. 55 789-795. doi: 10.1016/j.neuint.2009.08.001

Ouellet, D., Sutherland, S., Wang, T., Griffini, P., and Murthy, V. (2011). First-timein-human study with GSK1018921, a selective GlyT1 inhibitor: relationship between exposure and dizziness. Clin. Pharmacol. Ther. 90, 597-604. doi: $10.1038 /$ clpt.2011.154

Park, K. M., Kim, J. J., Seok, J. H., Chun, J. W., Park, H. J., and Lee, J. D. (2009). Anhedonia and ambivalence in schizophrenic patients with fronto-cerebellar metabolic abnormalities: a fluoro-d-glucose positron emission tomography study. Psychiatry Investig. 6, 72-77. doi: 10.4306/pi.2009.6.2.72

Peleg-Raibstein, D., Feldon, J., and Meyer, U. (2012). Behavioral animal models of antipsychotic drug actions. Handb. Exp. Pharmacol. 212, 361-406. doi 10.1007/978-3-642-25761-2_14

Pinkham, A., Loughead, J., Ruparel, K., Wu, W. C., Overton, E., and Gur, R. (2011). Resting quantitative cerebral blood flow in schizophrenia measured by pulsed arterial spin labeling perfusion MRI. Psychiatry Res. 194, 64-72. doi: 10.1016/j.pscychresns.2011.06.013
Porras, G., De Deurwaerdere, P., Moison, D., and Spampinato, U. (2003). Conditional involvement of striatal serotonin 3 receptors in the control of in vivo dopamine outflow in the rat striatum. Eur. J. Neurosci. 17, 771-781. doi: 10.1046/j.1460-9568.2003.02512.x

Roberts, P. D., Spiros, A., and Geerts, H. (2012). Simulations of symptomatic treatments for Alzheimer's disease: computational analysis of pathology and mechanisms of drug action. Alzheimers. Res. Ther. 4, 50. doi: 10.1186/ alzrt153

Rosenbaum, B., Harder, S., Knudsen, P., Koster, A., Lindhardt, A., Lajer, M., et al. (2012). Supportive psychodynamic psychotherapy versus treatment as usual for first-episode psychosis: two-year outcome. Psychiatry 75, 331-341. doi: 10.1521/psyc.2012.75.4.331

Shen, W., Hamilton, S. E., Nathanson, N. M., and Surmeier, D. J. (2005) Cholinergic suppression of KCNQ channel currents enhances excitability of striatal medium spiny neurons. J. Neurosci. 25, 7449-7458. doi: 10.1523/JNEUROSCI.1381-05.2005

Shen, W., Tian, X., Day, M., Ulrich, S., Tkatch, T., Nathanson, N., et al. (2007). Cholinergic modulation of Kir2 channels selectively elevates dendritic excitability in striatopallidal neurons. Nat. Neurosci. 10, 1458-1466. doi: 10.1038/ nn1972

Singh, S. P., and Singh, V. (2011). Meta-analysis of the efficacy of adjunctive NMDA receptor modulators in chronic schizophrenia. CNS Drugs 25, 859-885. doi: 10.2165/11586650-000000000-00000

Slifstein, M., Kolachana, B., Simpson, E. H., Tabares, P., Cheng, B., Duvall, M. et al. (2008). COMT genotype predicts cortical-limbic D1 receptor availability measured with [11C]NNC112 and PET. Mol. Psychiatry 13, 821-827. doi: 10.1038/mp.2008.19

Sorg, C., Manoliu, A., Neufang, S., Myers, N., Peters, H., Schwerthoffer, D., et al. (2013). Increased intrinsic brain activity in the striatum reflects symptom dimensions in schizophrenia. Schizophr. Bull. 39, 387-395. doi: $10.1093 / \mathrm{schbul} / \mathrm{sbr} 184$

Sotero, R. C., and Trujillo-Barreto, N. J. (2007). Modelling the role of excitatory and inhibitory neuronal activity in the generation of the BOLD signal. Neuroimage 35, 149-165. doi: 10.1016/j.neuroimage.2006.10.027

Sotero, R. C., and Trujillo-Barreto, N. J. (2008). Biophysical model for integrating neuronal activity, EEG, fMRI and metabolism. Neuroimage 39, 290-309. doi: 10.1016/j.neuroimage.2007.08.001

Spiros, A., Carr, R., and Geerts, H. (2010). Not all partial dopamine D(2) receptor agonists are the same in treating schizophrenia. Exploring the effects of bifeprunox and aripiprazole using a computer model of a primate striatal dopaminergic synapse. Neuropsychiatr. Dis. Treat. 6, 589-603. doi: 10.2147/NDT.S12460

Spiros, A., Roberts, P., and Geerts, H. (2012). A quantitative systems pharmacology computer model for schizophrenia efficacy and extrapyramidal side effects. Drug Dev. Res. 73, 196-213. doi: 10.1002/ddr.21008

Strong, A. J., and Dardis, R. (2005). Depolarisation phenomena in traumatic and ischaemic brain injury. Adv. Tech. Stand. Neurosurg. 30, 3-49. doi: 10.1007/3211-27208-9_1

Sugita, S., Uchimura, N., Jiang, Z. G., and North, R. A. (1991). Distinct muscarinic receptors inhibit release of gamma-aminobutyric acid and excitatory amino acids in mammalian brain. Proc. Natl. Acad. Sci. U.S.A. 88, 2608-2611. doi: 10.1073/pnas.88.6.2608

Tsai, G., Lane, H. Y., Yang, P., Chong, M. Y., and Lange, N. (2004). Glycine transporter I inhibitor, N-methylglycine (sarcosine), added to antipsychotics for the treatment of schizophrenia. Biol. Psychiatry 55, 452-456. doi: 10.1016/j.biopsych.2003.09.012

Tsuda, Y., Saruwatari, J., and Yasui-Furukori, N. (2014). Meta-analysis: the effects of smoking on the disposition of two commonly used antipsychotic agents, olanzapine and clozapine. BMJ Open 4:e004216. doi: 10.1136/bmjopen-2013 004216

van den Buuse, M., Halley, P., Hill, R., Labots, M., and Martin, S (2012). Altered N-methyl-D-aspartate receptor function in reelin heterozygous mice: male-female differences and comparison with dopaminergic activity. Prog. Neuropsychopharmacol. Biol. Psychiatry 37, 237-246. doi: 10.1016/j.pnpbp.2012.02.005

Weinberger, D. R. (2007). Schizophrenia drug says goodbye to dopamine. Nat. Med. 13, 1018-1019. doi: 10.1038/nm0907-1018

Winterer, G., Ziller, M., Dorn, H., Frick, K., Mulert, C., Wuebben, Y., et al. (2000). Schizophrenia: reduced signal-to-noise ratio and impaired 
phase-locking during information processing. Clin. Neurophysiol. 111, 837-849. doi: 10.1016/S1388-2457(99)00322-3

Wolkenberg, S. E., and Sur, C. (2010). Recent progress in the discovery of nonsarcosine based GlyT1 inhibitors. Curr. Top. Med. Chem. 10, 170-186. doi: 10.2174/156802610790410974

Wolkin, A., Sanfilipo, M., Wolf, A. P., Angrist, B., Brodie, J. D., and Rotrosen, J. (1992). Negative symptoms and hypofrontality in chronic schizophrenia. Arch. Gen. Psychiatry 49, 959-965. doi: 10.1001/archpsyc.1992.01820120047007

Woodward, R. M., Huettner, J. E., Guastella, J., Keana, J. F., and Weber, E. (1995). In vitro pharmacology of ACEA-1021 and ACEA-1031: systemically active quinoxalinediones with high affinity and selectivity for $\mathrm{N}$-methyl-D-aspartate receptor glycine sites. Mol. Pharmacol. 47, 568-581.

Yang, C. R., and Seamans, J. K. (1996). Dopamine D1 receptor actions in layers V-VI rat prefrontal cortex neurons in vitro: modulation of dendritic-somatic signal integration. J. Neurosci. 16, 1922-1935.

Zhang, Y., Buonanno, A., Vertes, R. P., Hoover, W. B., and Lisman, J. E. (2012). NR2C in the thalamic reticular nucleus; effects of the NR2C knockout. PLoS ONE 7:e41908. doi: 10.1371/journal.pone.0041908
Conflict of Interest Statement: All authors are employees of In Silico Biosciences. Hugo Geerts and Athan Spiros are the inventors on two patents related to Quantitative Systems Pharmacology.

Received: 10 June 2014; accepted: 23 September 2014; published online: 21 October 2014.

Citation: Spiros A, Roberts $P$ and Geerts $H$ (2014) A computer-based quantitative systems pharmacology model of negative symptoms in schizophrenia: exploring glycine modulation of excitation-inhibition balance. Front. Pharmacol. 5:229. doi: 10.3389/ fphar.2014.00229

This article was submitted to Experimental Pharmacology and Drug Discovery, a section of the journal Frontiers in Pharmacology.

Copyright (๑) 2014 Spiros, Roberts and Geerts. This is an open-access article distributed under the terms of the Creative Commons Attribution License (CC BY). The use, distribution or reproduction in other forums is permitted, provided the original author(s) or licensor are credited and that the original publication in this journal is cited, in accordance with accepted academic practice. No use, distribution or reproduction is permitted which does not comply with these terms. 